\title{
The effect of ethanol gasoline on particulate emissions for GDI engine
}

\author{
Shijie Qiao, Jun Li, Yu Liu*
}

State Key Laboratory of Automotive Simulation and Control, Jilin University, Changchun, 130025, China

Keywords: Particle; mass concentration; number concentration.

\begin{abstract}
The particulate emission of GDI gasoline haven't been paid special attention to due to the lower significantly particulate emissions than that of diesel engines. But in the last few years, some studies have shown that the particulate of gasoline engine have carried more harmful substances which can penetrate the lungs, in consideration of the case that the same mass of particle has larger surface area with smaller size. The high octane and good anti-knock make the blend of ethanol gasoline get widely use. We use EEPS and build a two stage dilution system to determine mass concentration and number concentration of particulate emissions of the E10 / E20 / E30 in the 1.4T engine. It was found that increasing the concentration of ethanol have good effect on reducing the mass concentration and number concentration of particulate emissions.
\end{abstract}

\section{Introduction}

With the increase in car ownership year by year, the issues of energy and environment have become obviously prominent, and energy-saving and emission reduction has become one of the chief indicators in the process of purchasing cars, therefore, GDI engine become the first choice with its excellent economy and great power. However, the fact that the spray characteristics of GDI engines is similar to that of the diesel engines makes the time of gas mixture in the cylinders get shorter and the concentration thicker locally for the gasoline engines, increasing the quality and quantity of particles generated for transient conditions, especially particle size less than $100 \mathrm{~nm}$, and these ultrafine particles is seriously harmful to human body, which have the bad effects on the human respiratory system, cardiovascular and nervous system of the human body as well as lead to DNA damage, carcinogenic and mutagenic effects. With the increasingly stringent emission regulations, ethanol gasoline, relying on high octane and good anti-knock, has been widely used. In this article, with the help of bench means, using 1.4T engine, respectively, using E10 / E20 / E30 ethanol fuel, particulate emission characteristics is measured.

\section{Experimental}

\section{Engine Setup and Operating Conditions}

Test bench consists of direct injection gasoline engine, EEPS-3090-type particle size of the spectrometer, AVL gas analysers, exhaust dilution system, CO2 testing equipment and other components. During the experiment, test bench is set at different driving conditions by control system and diluted exhaust particle concentration and particle size distribution are measured by the spectrometer, the exhaust dilution system contains spectrometer and other testing equipment which is used to provide diluted exhaust gas. The sample of exhaust gas is obtained at the exhaust pipe and then is diluted into dilution gas by the two stage dilution system. Finally, using the spectrometer analyses the dilution gas. 


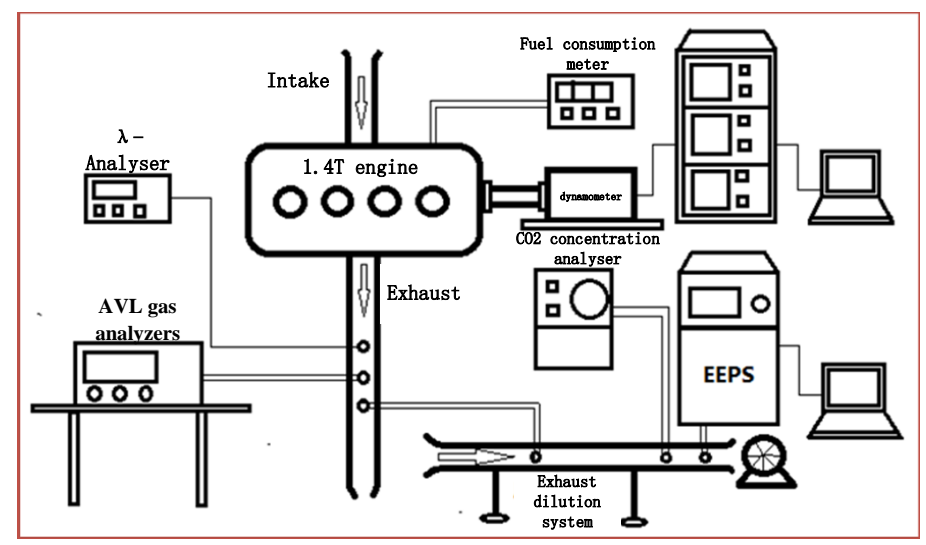

Figure 1 shows schematic diagram of the experimental system. The relevant parameters of experimental engine are listed in Table 1.

Table 1 the parameters for test engine

\begin{tabular}{|c|c|c|c|}
\hline Supply System & GDI & Cycle & 4 stroke \\
\hline Vavle System & DOHC & Compression ratio & $10: 1$ \\
\hline Max Power & $96 \mathrm{kw}$ & Max Speed & $200 \mathrm{~km} / \mathrm{h}$ \\
\hline Max Torque & $260 \mathrm{Nm}$ & Number of Cylinders & 4 \\
\hline
\end{tabular}

\section{Dilution system}

The sample for exhaust gas needs to be diluted into a certain range of concentration in order to be measured accurately by instrument. Two stage dilution system is used to dilute sample of exhaust gas. Firstly, the collected exhaust go through passage to finish the primary, and then the diluted mixture is conveyed together to the secondary dilution system. Finally, particle measurement device can capture the diluted gas from outlet of the dilution system to determine the distribution of the size and mass. The key is to adjust the dilution ration, which can be controlled by changing the intake valve opening and valve opening for sampling at the exhaust pipe, and then we calculate the dilution ration with the $\mathrm{CO} 2$ concentration after and before dilution according the formula.......

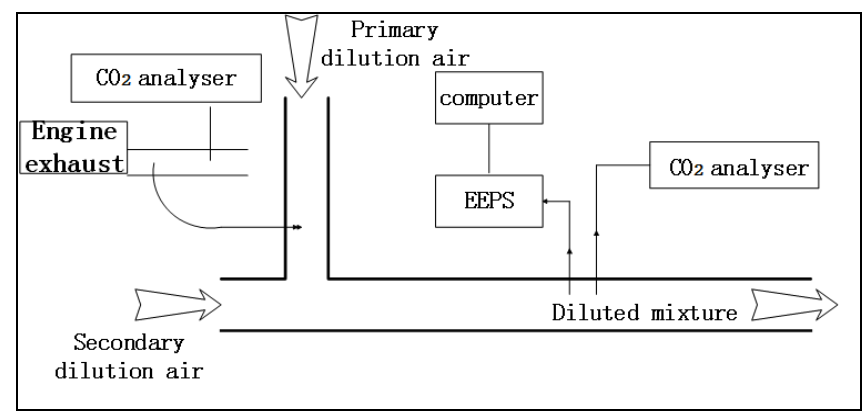

Figure 2 shows exhaust dilution system

\section{Results and discussion}

From the figure 3, normally the running speed is low at idle, and in-cylinder gas flow is weak, at the same time the amount of residual gas is the greater, resulting in the deterioration of fuel atomization and incomplete combustion; and at this time the lower in-cylinder combustion temperature is not favour to the particulate matter oxidation; while at low load unburned lubricating oil will produce more nuclear mode particulates; but adding a reasonably higher proportion of ethanol can make the mass of particles and the number of nuclear mode reduction. According to the comparison the combustion equation of ethanol gasoline with that of gasoline, adding ethanol into gasoline is equivalent to the improvement in the content of 02 , making the gasoline tend to be more complete in the combustion process and reducing the formation of dry soot, making the nucleation effect of the accumulation mode weakened. 


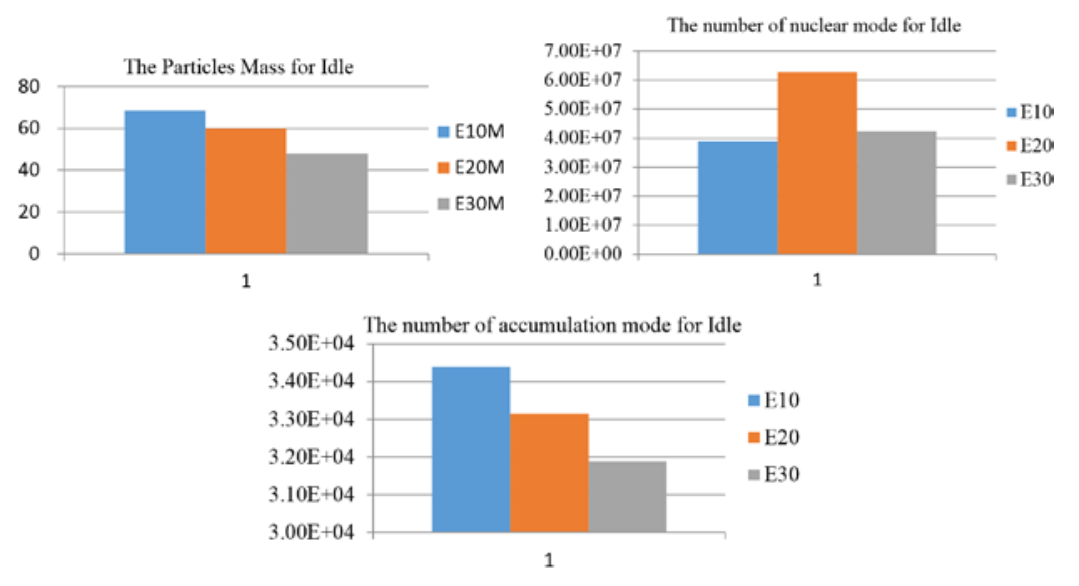

Figure 3 shows the emission characteristics during idle periods using E10 / E20 / E30 ethanol gasoline respectively: first picture represents particles mass during idle; the second is the number of nuclear particles that corresponds to the idle state and the third is the number of accumulation particles of the number at idle speed.

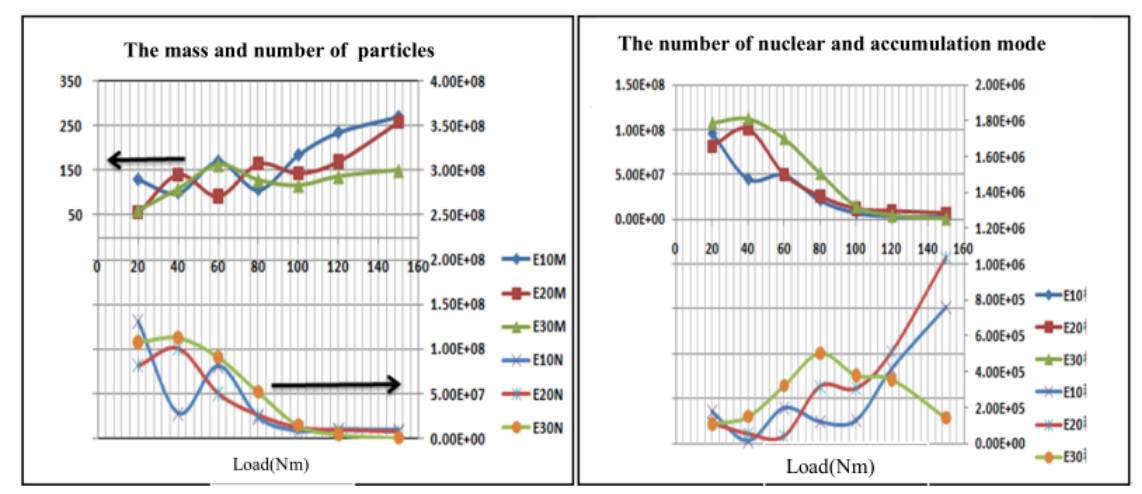

Figure 4 shows the emission characteristics at the speed of 1000r/min using E10 / E20 / E30 ethanol respectively for GDI engine. The upper three plots of the first piece reflected the total mass of particulate when using E10 / E20 / E30 , the lower three plots of first piece exemplified the total number of generated particles; The upper three curves on the second picture corresponded to the number of generated nuclear particles, the lower the three curves on the second picture showed the number of accumulation mode.

Figure 4 tells us that the whole particles mass increases with the increase of the load, and the number of particles generated can be reduced with the increase of the load, which is due to the increased loads results in the advancement of combustion chamber temperature, such that the temperature of combustion is moving towards a direction of high temperature, which improves the probability of the oxidation of the HC produced in cylinder and weakens the tendency that HC accumulates to nucleate, and cuts down the concentration of HC, thereby the number of nuclear states is reduced, and the total number of particles depends primarily on the number of nuclear states; But comparing the data for the each operating point when using E10 / E20 / E30 respectively, it's not difficult to find that the increase of ethanol concentration leads to the reduction of the quality of the generated particles, which further validates that the addition of ethanol is equivalent to the advancement of the intake air, so that some HC have been oxidized, thereby reducing the quality and quantity of generated particles; However the number of accumulation mode rises as the load increases, which is the reason that the thermal cracking of in-cylinder fuel and dehydrogenation at high temperature lead to producing primary soot particles which are made easy to become accumulation mode particles by agglomeration and adsorption of substances such as HC. But compared with the number of accumulation mode generated for different concentration ethanol gasoline , the fact has been found that the higher concentration ethanol gasoline improve the oxygen content, so that the portion of primary soot particles has been oxidated, and the number of accumulation mode for E30 is smaller than that for E10 and E20. Since the magnitude of quantity of nuclear mode is much larger than that of accumulation mode, so the particle size distribution remain 
a unimodal distribution, and the improvement of accumulation mode haven't led to the addition of the total number of particles. Further describing, the number of nuclear mode determines the total number of particles.

On the whole, from figure 5,the mass of generated particles gradually reduces as the load increases, and at small load, the mass of particles for E30 is lower; when at high load, the effect of ethanol concentration on the mass of generated particles becomes gradually smaller, which is due to the increase of the combustion temperature that makes partial the particles oxidation, thereby this difference decreases; the total number of particles also decreased slowly with increase of the load; But at full load, the total number of particles have a certain level of improvement; the number of nuclear mode also decrease as the load increases; overall the quantity of accumulation mode keeps decreasing with the load gradually decrease, obviously increase of the ethanol concentration does reduce the number of the accumulation mode, which is due to improvement of the fuel injection when load increase and bad mixture for fuel and air in the cylinder ;and high concentrations of ethanol gasoline makes the probability of the primary soot oxidation increase due to the higher oxygen content;
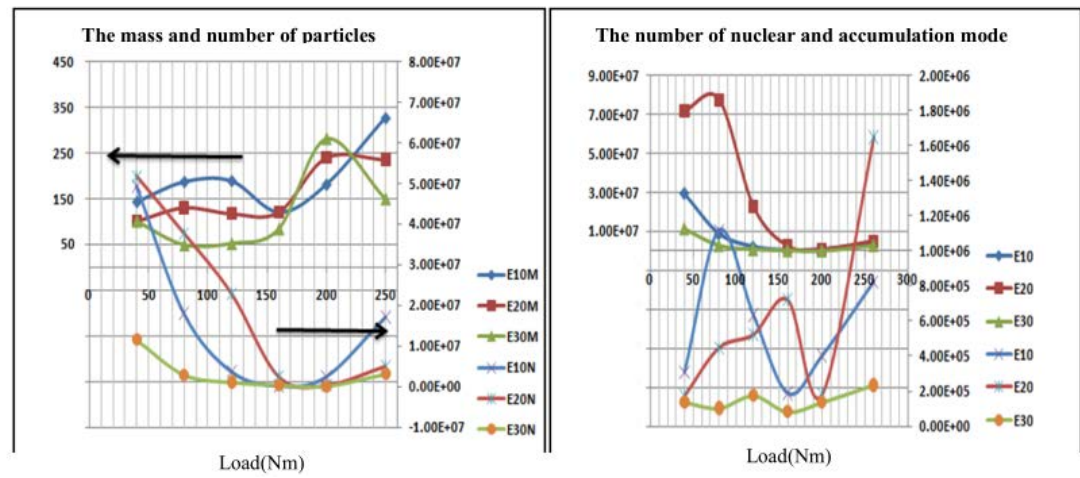

Figure 5 shows the particulate emission characteristics at the speed of 2000r/min for E10 / E20 / E30 ethanol gasoline. The upper three plots of first piece represented the total mass of particulate for E10 / E20 / E30;the lower three plots of the first piece reflected the total number of generated particles using E10/E20/E30; The upper three curves on the second picture corresponds to the number of nuclear mode for E10 / E20 / E30, the lower three curves were a corresponding number of accumulation mode using E10 / E20 / E30.
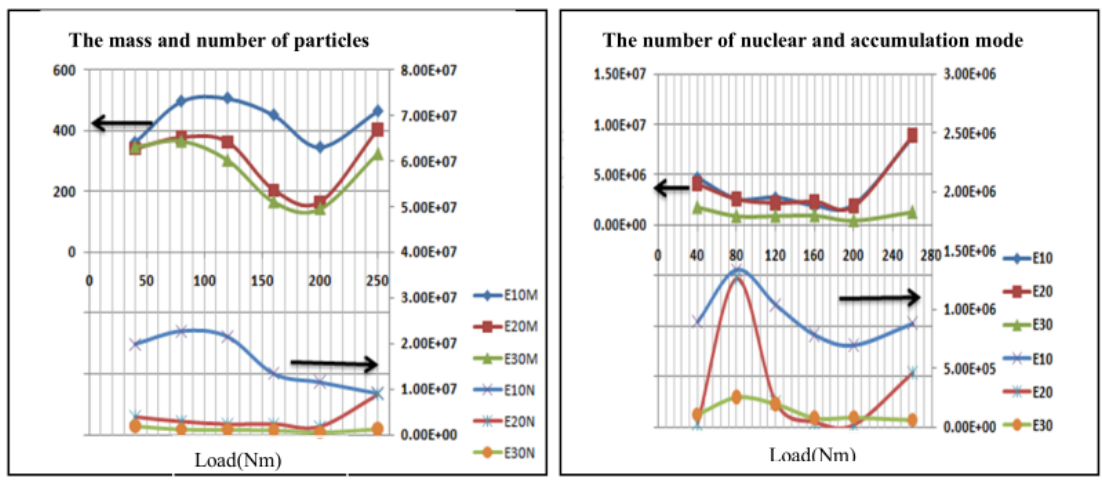

Figure 6 shows the particulate emission characteristics at the speed of 3000r/min for E10 / E20 / E30 ethanol gasoline. The upper three plots of first piece reflected the total mass of particles for E10 / E20 / E30 ; the lower three plots of first piece represented the total number of generated particles; The upper three curves on the second picture corresponds to the number of nuclear using E10/E20/E30; the lower three curves on the second picture were a corresponding number of accumulation mode usingE10 / E20 / E30.

As we can see from figure 6, at the speed of 3000r/min, no matter how small or large load it is, it is obvious that ethanol has good effect on reducing the mass of particulates; At the medium and small load, the mass of generated particles decreases with increasing load, but at full load, the excess air ratio is about 0.92 due to the rich mixture, resulting in incomplete combustion; At the speed of $3000 \mathrm{r} / \mathrm{min}$, the orders of magnitude of nuclear mode are the same as the orders of 
magnitude of accumulation mode, which shows a bimodal distribution; At full load, accumulation mode improves significantly, which is due to the use of enriched mixture and the wet wall, leading to reinforcing the tendency of incomplete combustion and a further increase in the number of accumulation mode particles; compare the datum for different concentrations of ethanol gasoline, it is found that the addition of ethanol has obvious influence on reducing the mass and quantity of particles.

\section{Conclusion}

At the speed of idle, $1000 \mathrm{r} / \mathrm{min}$ and $2000 \mathrm{r} / \mathrm{min}$, the exhaust particulate size for tested GDI engine shows the unimodal distribution; At the speed of 3000r/min,it reflected the bimodal distribution; and the ratio of the number of nuclear mode is greater than that of the number of accumulation mode, while the ratio of the mass of accumulation mode is greater than that of the mass of nuclear states; the number of nuclear mode decreases gradually with load increase, but when the mixture is enriched, the number of nuclear mode will increase;

According to the comparison of ethanol gasoline combustion equation and gasoline combustion equation, it is confirmed that the use of ethanol gasoline is equivalent to increasing the amount of intake air, thereby improving combustion, so that part of the particulates get further combustion, reducing particulate emissions mass and quantity.

\section{Acknowledgments}

This work was supported by the National Natural Science Foundation of China (Grant No. 51306069) and International Science \& Technology Cooperation Program of China (Grant No. 2014DFA91200).The first project is "Optical Research on Particulate Matter Generation Process under GDI engine Transient Conditions" and the second is "Research on key technology of offengine Purification of GDI engines for PM2.5”.

\section{References}

[1] Albuquerque, P. C., Ávila, R. N., Zárante, P. H. and Sodré,J. R. (2011). Lubricating oil influence on exhaust hydrocarbon emissions from a gasoline fueled engine.Tribology Int., 44, 1796-1799.

[2] Berndorfer, A., Breuer, S., Piock, W. and Bacho, P. V.(2013). Diffusion combustion phenomena in GDIengines caused by injection process. SAE Paper No.2013-01-0261.

[3] Eastwood, P. (2008). Particulate Emissions from Vehicles.John Wiley \& Sons Ltd. UK.

[4] CARB (2010). Proposed amendments to California's low-emission vehicle regulations Particulate matter mass,ultrafine solid particle number, and black carbon emissions. Preliminary Discussion Paper.

[5] Fushimia, A., Saitoha, K., Fujitania, Y., Hasegawaa, S.,Takahashid, K., Tanabea, K. and Kobayashia, S. (2011).Organic-rich nanoparticles (diameter: 10-30 nm) in diesel exhaust: Fuel and oil contribution based on composition. Atmos. Environ., 45, 6326-6336.

[6] Choi, K., Kim, J., Ko, A., Myung, C. L., Park, S. and Lee,J. (2013). Size-resolved engine exhaust aerosol characteristics in a metal foam particulate filter for GDI light-duty vehicle. J. Aerosol Sci., 57, 54-70.

[7] Hassaneen, A. E., Samuel, S. and Whelan, I. (2011).Combustion instabilities and nanoparticles emission fluctuations in GDI spark ignition engine. Int. J.Automotive Technology 12, 6, 787-794.

[8] Johnson, K. C., Thomas, D., Durbin, T. G., Jung, H.Cocker, D. R., Bishnu, D. and Giannelli, R. (2011).Quantifying in-use PM measurements for heavy duty diesel vehicles. Environ. Sci. Technol., 45, 6073-6079.

[9] Kern, B., Spiess, S. and Richter, J. M. (2013). The challenge of emission legislation EU6c for 
gasoline-DI-engines, strategies meeting the new demands andpreparing for extended test conditions. 22nd AachenColloquium.

[10] Kim, J., Choi, K., Myung, C. L. and Park. S. (2013c).Experimental evaluation of engine control strategy on the time resolved THC and nano-particle emission characteristics of liquid phase LPG direct injection (LPG-DI) engine during the cold start. Fuel Processing Technology, 106, $166-173$.

[11] Ko, A., Kim, J., Choi, K., Myung, C. L., Kwon, S., Kim,K., Cho, Y. J. and Park, S. (2012). Experimental study of particle emission characteristics of a heavy-duty diesel engine and effects of after-treatment systems: Selective catalytic reduction, diesel particulate filter, and diesel particulate and NOx reduction. J. Automobile Engineering 226, 12, 1689-1696.

[12] Mamakos, A., Martini, G. and Manfredi, U. (2013b).Assessment of the legislated particle number measurement procedure for a Euro 5 and a Euro 6 compliant diesel passenger cars under regulated and unregulated conditions.J. Aerosol Sci., 55, 31-47.

[13] Momenimovahed, A., Olfert, J. S., Checkel, M. D., Pathak,S., Sood, V., Robindro, L., Singal, K., Jain, A. K. and Garg, O. (2013). Effect of fuel choice on nanoparticle emission factors in LPGgasoline bi-fuel vehicles. Int. J.Automotive Technology 14, 1, 111.

[14] Myung, C. L., Choi, K., Kim, J., Lim, Y., Lee, J. and Park,S (2012a). Comparative study of regulated and unregulated toxic emissions characteristics from a spark ignition direct injection lightduty vehicle fueled with gasoline and liquid phase LPG (liquefied petroleum gas). Energy, 44, 189-196.

[15] Stetter, J., Forster, N., Ghandhi, J. and Foster, D. (2003) The impact of oil consumption mechanisms on diesel exhaust particle size distributions and detailed exhaust chemical composition. DEER Conf.

[16] Thiruvengadam, A., Besch, M., Carder D., Oshinuga, A. and Gautam, M. (2012). Influence of real-world engine load conditions on nanoparticle emissions from a DPF and SCR equipped heavyduty diesel engine. Environ. Sci. Technol., 46, 1907-1913.Weiss, M., Bonnel, P., Kühlwein, J., Provenza, A., Lambrecht, U., Alessandrini, S.,

[17] Carriero, M., Colombo, R., Forni, P., Lanappe, G., Lijour, P. L., Manfredi, U., Montigny, F. and Sculati, M. (2012). Will Euro 6 reduce the NOx emissions of new diesel cars? - Insights from onroad tests with portable emissions measurement systems (PEMS). Atmos. Environ., 62, 657-665. 